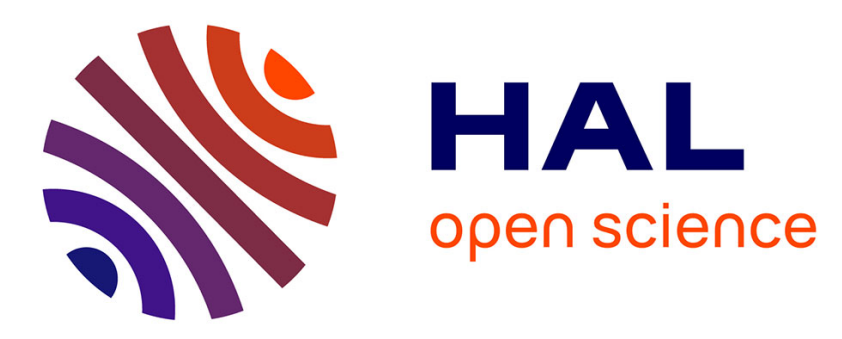

\title{
Combined standard(SPPE) and inverse(IPPE) photopyroelectric configurations for measurement of dynamic thermal parameters of saturated and unsaturated fatty acids
}

\author{
D. Dadarlat, H. Visser, D. Bicanic, A. Frandas, K. van Asselt
}

\section{To cite this version:}

D. Dadarlat, H. Visser, D. Bicanic, A. Frandas, K. van Asselt. Combined standard(SPPE) and inverse(IPPE) photopyroelectric configurations for measurement of dynamic thermal parameters of saturated and unsaturated fatty acids. Journal de Physique IV Proceedings, 1994, 04 (C7), pp.C7483-C7-486. 10.1051/jp4:19947113 . jpa-00253166

\section{HAL Id: jpa-00253166 https://hal.science/jpa-00253166}

Submitted on 1 Jan 1994

HAL is a multi-disciplinary open access archive for the deposit and dissemination of scientific research documents, whether they are published or not. The documents may come from teaching and research institutions in France or abroad, or from public or private research centers.
L'archive ouverte pluridisciplinaire HAL, est destinée au dépôt et à la diffusion de documents scientifiques de niveau recherche, publiés ou non, émanant des établissements d'enseignement et de recherche français ou étrangers, des laboratoires publics ou privés. 


\title{
Combined standard(SPPE) and inverse(IPPE) photopyroelectric configurations for measurement of dynamic thermal parameters of saturated and unsaturated fatty acids
}

\author{
D. Dadarlat, H. Visser*, D. Bicanic*, A. Frandas and K, van Asselt*
}

Institute for Isotopic and Molecular Technology, P.O. Box 700, 3400 Cluj-Napoca, Romania

* Laser Photoacoustic Laboratory, Department of Agricultural Engineering and Physics, Wageningen

Agricultural University, Bomenweg 4, 6703 HD Wageningen, The Netherlands

\begin{abstract}
Combined SPPE-IPPE method is proposed to obtain thermal parameters (thermal effusivity, diffusivity, conductivity and volume specific heat) of saturated (caproic C10:0) and monoenoic unsaturated (oleic C18:1, cis) fatty acids. The method was also used to investigate temperature behaviour of thermal parameters (around the melting point) for lauric acid (C12:0). The combined SPPE-IPPE approach eliminates problems associated with sample's transparency and thickness control.
\end{abstract}

\section{INTRODUCTION}

An important aspect of industrial processing of edible oils and fats is the ability to measure their physical properties in a rapid, sensitive, and reproducible fashion. Traditional methods are elaborate, time consuming, and costly; development of alternative techniques is encouraged.

In principle standard photopyroelectric (SPPE) and inverse photopyroelectric (IPPE) configurations allow each the measurement of two thermal parameters (the remaining two are then calculated) provided that certain experimental conditions are met [1,2] i.e. : i) sample is optically opaque (SPPE); ii) thickness of the sample is rigorously controlled (both SPPE, IPPE), and iii) sensor is thermally thin (IPPE).

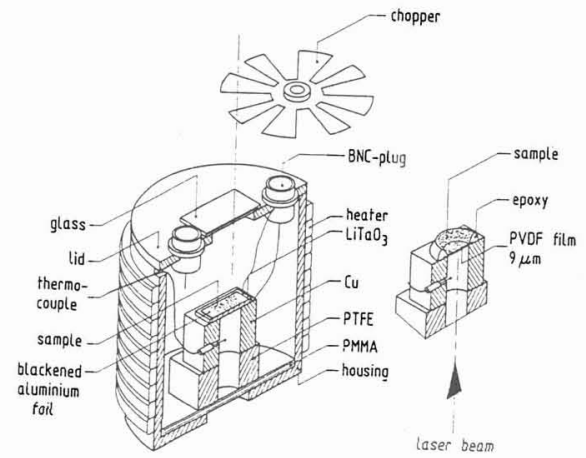

Fig. 1 The SPPE-IPPE cell used in this study.

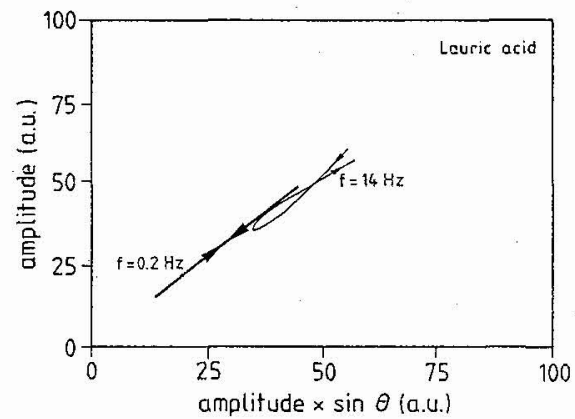

Fig. 2 Amplitude of SPPE signal for C12:0 versus quadrature component at two modulation frequencies. 
When sample is partially transparent and undergoes a solid to liquid phase transition, the above mentioned conditions are not easily met anymore so that either filters or quite sophisticated PPE cell geometries are required. Combining two configurations (as proposed in this paper) is a good alternative for some limiting PPE cases.

\section{THEORY}

In the standard configuration, when the sensor is thermally thick, and sample both thermally thin and optically opaque, the magnitude of PPE signal is given by [3]:

$$
V=\frac{V_{o s}}{C_{s}} \cdot e^{-i \frac{3 \pi}{4}} ; V_{o s}=\frac{p H_{o}}{2 \sqrt{2} \epsilon \omega a_{p} I_{s}}
$$

In the IPPE scheme, when sample is thermally thick, the PPE signal can be calculated from [2]:

$$
V=\frac{V_{o i}}{e_{s}} e^{i \frac{\pi}{4}} ; V_{o i}=\frac{\tau_{E} p(1-R) H_{o}}{\sqrt{2} \epsilon C_{p}} \cdot e_{p} a_{p} L_{p}
$$

In eqs.(1) and (2) conventional symbols were used to characterize various physical quantities. As seen from eqs. (1) and (2) relevant information is contained in the amplitude term of the PPE signal, while the phase is constant. In both cases the amplitude of the signal depends in a very simple manner (inversely proportional) on a sample related thermal parameter: volume specific heat (SPPE) or thermal effusivity (IPPE).

Remaining two parameters (thermal diffusivity $\alpha$ and thermal conductivity $\mathrm{k}$ ) are evaluated using well known relationships:

$$
C=\frac{k}{\alpha} ; e=(C \cdot k)^{\frac{1}{2}}
$$

\section{EXPERIMENTAL}

Specially designed SPPE-IPPE cell is shown in Fig. 1. The sensors used in the experiment were 300 $\mu \mathrm{m}$ thick $\mathrm{LiTaO}_{3}$ (SPPE) and a $9 \mu \mathrm{m}$ thick PVDF foil (IPPE). In the SPPE configuration the requirement for opacity of sample was achieved by using a blackened $\mathrm{Al}$ foil in a good thermal contact with sample. In this configuration thickness of sample is unknown, but included in the calibration factor $\mathrm{V}_{\text {os. }}$. To calibrate the measurements of volume specific heat, literature values (at room temperature) were used for each sample [4]. Due to the fact that sample's thickness is unknown, the constancy of the phase (which confirms that sample indeed is thermally thin) must be verified prior to taking the measurement (Fig. 2). In the IPPE scheme the sensor is opaque and thermally thin for frequencies below $200 \mathrm{~Hz}$. The sample (typically $3 \mathrm{~mm}$ thick) is thermally thin for frequencies higher than 0.01 $\mathrm{Hz}$. Consequently, chopping frequencies of $0.2 \mathrm{~Hz}$ (SPPE) and $0.1 \mathrm{~Hz}$ (IPPE) were chosen to satisfy validity criteria imposed by eqs. (1) and (2). Water, the thermal effusivity of which is accurately known at room temperature, [5] was used to calibrate the IPPE measurement.

For solid samples at room temperature (such as $\mathrm{C12:0}$ ), the cell was first heated to a temperature exceeding melting point and then cooled down slowly again in order to assure a uniform thickness and 
a good thermal contact between sensor, sample and Al foil. The temperature variation rate was 1 ${ }^{\circ} \mathrm{C} / \mathrm{min}$.

\section{RESULTS}

The results are shown in Figs. 3-6. No important changes in temperature behaviour of volume specific heat and thermal effusivity in the $20-60^{\circ} \mathrm{C}$ temperature range for caproic and oleic acids were found, while sharp anomalies were observed in a critical region for lauric fatty acid.

As mentioned above, remaining thermal parameters can be calculated by means of eq. 3. Thermal conductivity of investigated samples is displayed in Figs. 7 and 8.

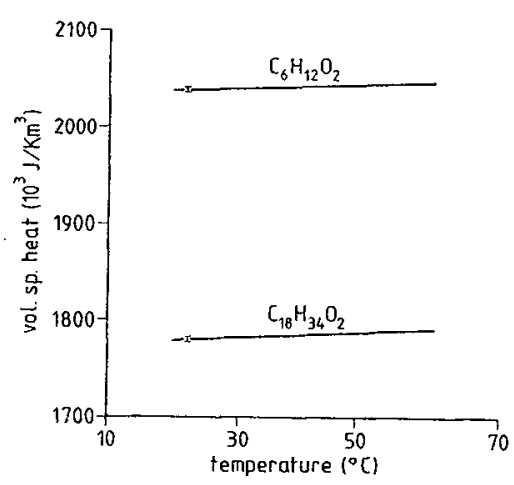

Fig. 3 The temperature behaviour of volume specific heat for caproic and oleic acids.

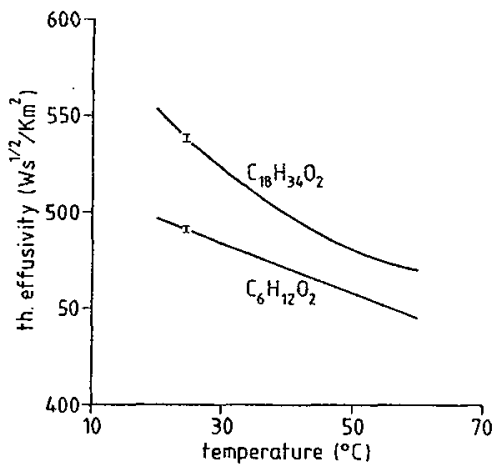

Fig. 5 The temperature behaviour of the thermal effusivity for caproic and oleic fatty acids.

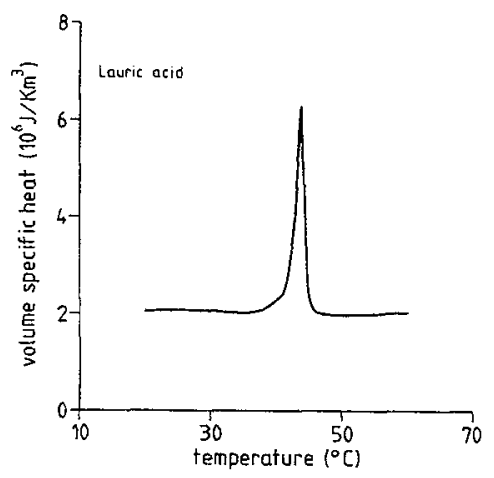

Fig. 4 The temperature behaviour of the volume specific heat for lauric acid.

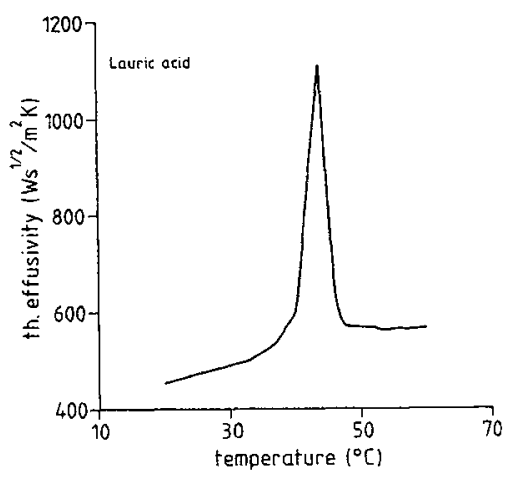

Fig. 6 The temperature behaviour of the thermal effusivity for lauric acid. 


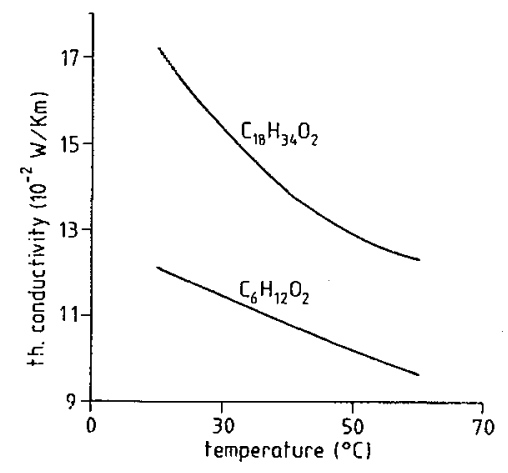

Fig. 7 Calculated thermal conductivity for caproic and oleic acids.

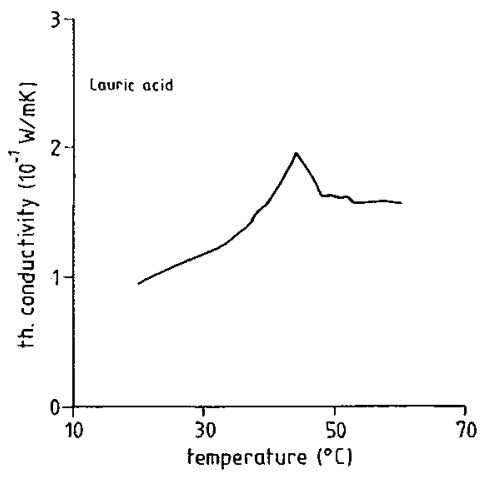

Fig. 8 Calculated thermal conductivity for lauric acid.

\section{CONCLUSIONS}

A new method based on a combined SPPE-IPPE configurations was proposed for investigating temperature behaviour of dynamic thermal parameters of lipids. This hyphenated technique allows a direct measurement of volume specific heat and of thermal effusivity; remaining two thermal parameters are then calculated. Previously unknown temperature behaviour data of dynamic thermal parameters for caproic, oleic and lauric fatty acids were obtained using this SPPE-IPPE approach.

\section{REFERENCES}

[1] Marinelli M., Zammit U., Mercuri F. and Pizzoferrato R., Journal of Applied Physics 72, (1992) 1096-1101.

[2] Dadarlat D. and Frandas A., Applied Physics A56 (1993) 235-257.

[3] Mandelis A., Care F., Chan K.K. and Miranda L.C., Applied Physics A38, (1985) 117-128.

[4] Fatty Acid Data Book, $3^{\text {rd }}$ Edition, Unichema International, Gouda, The Netherlands (1992)

[5] Bicanic D., Chirtoc M., Dadarlat D., van de Bovenkamp P. and van Schayk H., Applied Spectroscopy 46, (1992) 602-606. 